\title{
DE BATESON A INGOLD: PASSOS NA CONSTITUIÇÃO DE UM PARADIGMA ECOLÓGICO*
}

Otávio Velho

BATESON, Gregory. 2000 [1972]. Steps to an Ecology of Mind. Chicago: The University of Chicago Press.

INGOLD, Tim. 2000. The Perception of the Environment: Essays in Livelihood, Dw elling and Skill. London: Routledge.

A natureza científica das "ciências sociais" nunca deixou de ser um problema. Uma solução elegante, que vem do final do século XIX e é associada a Dilthey (e posteriormente a Weber), consistiu em distinguir as "ciências do espírito" (Geisteswissenschaften) das "ciências da natureza” (Naturwissenschaften). Essa solução, aparentemente nova, na verdade não fez mais do que se enquadrar num dos lados de uma oposição fundante entre natureza e cultura. Oposição que, juntamente com uma série de outras (como a entre sujeito e objeto e entre razão e emoção), parece fazer parte de um quadro que ganhou organização especial no século XVIII (sendo radicalizado no século seguinte) e que costuma ser associado à modernidade (quiçá, no caso, preferencialmente por sua via romântica). Um dos efeitos nas ciências sociais foi, também, erigir a interpretação como procedimento que se opõe à explicação, este último próprio às ciências da natureza.

Embora nem todos os antropólogos tenham aceito o rótulo de "interpretacionistas", talvez se possa considerá-lo como a formalização de um estilo que prevalece hoje de modo amplo entre nós, sobretudo na distinção com outros, mais antigos, como o da vertente "materialista", associada a autores como Marvin Harris, Leslie White e o primeiro Marshall Sahlins. Esse estilo se funda na aceitação de um grande divisor entre o nosso campo e o das ciências da natureza. E nisso também estaríamos seguindo tendências mais amplas, como a da influente caracterização de "duas culturas", a científica e a humanista-literária, feita por C. P. Snow (1959) e outros.

O fato de essa elegante solução se apoiar na oposição entre natureza e cultura não causou maior mossa até recentemente. Trata-se, afinal, 
de consagrada oposição, associada, entre outras, à obra de Claude LéviStrauss (para quem, no entanto, a oposição não se identifica com esse divisor) e que produziu frutos inegáveis. Diria, no entanto, que nos últimos anos novos ventos têm soprado. Ventos que, de certa forma, denunciam a contradição de uma postura que se quer à frente de outras, mais acomodadas, ao mesmo tempo que se apóia, sem se posicionar a esse respeito, no postulado de um iluminismo crescentemente desafiado.

É possível dizer-se que, de um ponto de vista estratégico, uma grande vantagem da postura interpretacionista foi a de erigir defesas contra as pretensões imperialistas provindas das ciências da natureza, sempre prontas a se manifestar entre nós através dos seus epígonos, na forma dos diversos "reducionismos". Mesmo que, num plano menos empírico, se possa considerar que até os diversos e legitimados sociologismos e culturalismos também terão sido tributários desse domínio, por se subordinarem à imagem comtiana dos níveis de complexidade. De qualquer forma, o preço a pagar por essa estratégia, afora a cisão ocorrida no interior da própria antropologia entre o seu lado sociocultural e o biológico, foi precisamente manter-se na defensiva, influindo pouco nos debates científicos contemporâneos. Ao entusiasmo ideológico pelo cientificismo, respondeu-se com uma recusa. Recusa que, na verdade, confirmava o cientificismo, por ignorar, paradoxalmente e no mesmo movimento, o diagnóstico da grande crise da ciência, feito desde Husserl. Crise, aliás, que talvez se pudesse considerar, hoje, como sendo sobretudo a das suas (auto-)imagens, camuflada pelo avanço espantoso da "ciência normal" possibilitada por novas tecnologias e que sugere a existência de uma prática científica que, pelo menos em parte, não se reduz a essas (auto-)imagens, ideologicamente poderosas.

Postura diferente teve Gregory Bateson (1904-1980). Por isso mesmo, de modo geral, considerou-se que após a publicação da sua monografia Naven, em 1936, esse antropólogo, filho de conhecido naturalista, teria, aos poucos, se afastado da antropologia. Diagnóstico que aparentemente o próprio Bateson não aceitou, pois sugeria que a antropologia é que o deixara (Harries-Jones 1995). O novo interesse que a sua obra vem despertando hoje, mesmo entre antropólogos (Bateson 2000), talvez seja indicação (e fonte) da mudança nos ventos.

O mais recente grande sinal desses novos ventos foi a publicação do livro de Tim Ingold, The Perception of the Environment: Essays in Livelihood, Dwelling and Skill (Ingold 2000). São 23 ensaios, em sua maioria novas versões de publicações anteriores, que constituem no conjunto a síntese de uma linha de trabalho amadurecida. De Bateson a Ingold, para 
além de importantes diferenças, percorre-se uma linha comum. Mas Ingold absorve, ainda, outras influências, como a de Maurice MerleauPonty. A fenomenologia da percepção de Merleau-Ponty (1971), deslocando o foco de análise de um ser abstrato que dá sentido ao mundo para um ser-no-mundo (e, ao contrário de outros filósofos, com profusão de exemplos concretos retirados da psicologia da Gestalt), é fundamental no desenvolvimento do pensamento de Ingold. Também o é o reencontro com a psicologia por via de sua vertente "ecológica" (Gibson 1986).

A ecologia - e com ela o holismo - é na verdade uma referênciachave desde Bateson. Faz parte da discussão de outra polaridade, entre sujeito e objeto. Com a ajuda da vertente fenomenológica de MerleauPonty (e das noções de ser e habitar o mundo), a ecologia de fato parece propícia para um deslocamento do sujeito cartesiano e, com ele, da série de oposições que inclui aquela entre natureza e cultura. Ingold chega a falar em um novo "paradigma ecológico" . Ecos de Espinosa, além de Heidegger.

É evidente que, dependendo do gosto, se pode igualmente acentuar as continuidades. O próprio Merleau-Ponty (1991) chamou a atenção para o interesse que nutria Lévi-Strauss pelas estruturas de parentesco complexas, onde não vige em termos absolutos o tabu do incesto e, portanto, a negação imediata da natureza. Nesse "segundo tipo de cultura", a tendência seria a um "corpo a corpo com a natureza", espécie de jogo, misto de artimanha e intimidade, que inclusive dá origem à ciência e aponta para uma relação mais geral de alteridade, de que a negação direta da natureza seria apenas um caso-limite. O homem e a sociedade, segundo Merleau-Ponty, passam, então, a ser reconhecidos como não estando exatamente fora da natureza e do biológico. E, na contramão do romantismo da antropologia, nossa sociedade ganha uma dignidade antropológica nova, expressa na prática científica. Deixa-se de obedecer mecanicamente a leis que, no fundo, funcionariam como se fossem as de uma segunda natureza que ocultaria a primeira (o que, diria Bateson, não significa que a primeira seja de fato tão mecânica). Surge, inclusive, pela primeira vez, a possibilidade de uma (multi)civilização mundial (outro tema atual), produto da flexibilização das fronteiras entre culturas ocorrida no mesmo processo.

Essas aproximações possíveis, no entanto, não reduzem a dramaticidade das diferenças existentes, se as encararmos como movimento mais geral, cujas vastas implicações a discussão acima permite vislumbrar. Mas a oposição mesma entre natureza-cultura se mostra menos direta, mais paradoxal. Como se a insistência na oposição ocultasse-revelasse 
uma dúvida de fundo sobre a realidade dessa separação, e a proposta de reencontro por sua vez implicasse uma nostalgia que revela-oculta uma separação que quer ser superada. Em ambos os casos, não são atos comunicativos constatativos ou performativos (no sentido dado por Austin) que estão em jogo, mas emotivos - o referente do enunciado mudando em função do próprio enunciado (Reddy 1997). A escolha por um dos lados (oposição ou não entre natureza e cultura) não é puramente objetiva, pois depende de inúmeros fatores em que o social e o individual se imbricam um no outro. E essa escolha é, de certa forma, política, por referir-se a modos de habitar o mundo, e não simplesmente a representações.

Fazendo prosa sem declará-lo, é possível que tudo isso já vá se refletindo, sub-repticiamente, no trabalho dos antropólogos. Refletindo-se mesmo, indiretamente, através de uma releitura do que pensam "nossos nativos" a respeito desses assuntos; o que constitui estratégia retórica eficaz entre nós, embora não constitua "prova necessária” para quem já desafia efetivamente o "paradigma da linguagem" e não supõe que o real se reduza ao discurso ou seja por ele espelhado ou produzido. Aliás, também pode ocorrer o reflexo desse movimento nas críticas atuais ao "construcionismo", que em suas várias vertentes parecia, há muito poucos anos atrás, ter dado um golpe mortal no "essencialismo" e com isso se estabelecido de vez num plano metateórico. Talvez o golpe tenha sido de fato desferido, mas isso aparentemente não representou o fim da história, e hoje abundam as tentativas de "síntese".

Na verdade, o construcionismo poderia ser reconhecido como uma das metamorfoses do niilismo, o qual não veria sentido no mundo. Contra isso hoje se apresentam noções como a de affordance (traduzível, talvez, como "propiciação") e que seria oferecida pelos objetos, lugares e eventos que nos cercam. Essa idéia é oriunda da psicologia ecológica (Gibson 1986), mas pretende-se estendê-la à antropologia por meio da noção de informação ecológica (Reed 1988). Esta e outras noções parecem ter relação com a crítica (não mencionada por Ingold) que Hans Jonas (1996) dirigiu a Heidegger e ao existencialismo, por negarem a relação entre o indivíduo e o cosmos, reminiscente, para ele, da gnose crítica dirigida também ao conseqüente não-reconhecimento da "existência” na natureza, ou seja, da capacidade desta para gerar valor (Jonas 1996; Velho 1998).

Não estaria em jogo, assim, um retorno ao essencialismo. Para Jonas, trata-se, justamente, de estender a existência à natureza, e, portanto, os limites do mundo que habitamos, embora ativamente. Construímos no mundo, que constitui um meio ambiente. E, com Bateson, trata-se de 
reconhecer que as propriedades não são das coisas em si, nem estão nelas; são apenas diferenças, e só existem em relação. Por outro lado, reconhece-se também que a experiência perceptiva pode ser subjetiva, mas não os processos que a engendram. Nem o primado do objeto, nem do sujeito. Daí a ênfase de Ingold na noção de skill, referida a habilidades aprendidas que incluiriam até mesmo supostas capacidades inatas, como andar ou falar.

Daí também a centralidade da comunicação, que não é apanágio dos seres humanos. Mas comunicação que se dá em múltiplos planos e que a mais das vezes, ao mesmo tempo que desafia as razões da lógica e da consciência - e, portanto, em termos mais radicais, o logocentrismo -, afirma a existência de sistemas autopoiéticos, auto-organizantes (na expressão dos biólogos chilenos Maturana e Varela (1980), que, no entanto, não acentuam a dimensão comunicativa). Tais sistemas se desenvolvem contra a tendência geral à entropia e definem unidades do processo evolutivo que vão muito além do que pretendem os darwinistas - o que seria consistente com um "paradigma ecológico" que reconheça (meta) padrões de conexão e processos de abdução (retomando noção de C. S. Peirce). De novo, ecos de Espinosa, mas através de Bateson.

Estamos longe, aqui, da exaltação da reflexividade e/ou da representação, abrindo-se espaço para o imenso terreno do " processo primário" , aparentado ao "pré-objetivo" de Merleau-Ponty. Terreno não do irracionalismo, mas das "razões do coração", na expressão de Pascal retomada repetidamente por Bateson (inclusive numa defesa do "intelectualismo" de Lévi-Strauss). Aqui, a metáfora e o simbolismo não existem como "figuras de linguagem", mas apenas se tomados como modo de comunicação vital, no seu sentido mais forte. Da mesma forma, pode-se contestar a associação permanente do biológico ao universal e do cultural ao particular, pois à medida que o biológico deixa de ser reduzido ao genético (redução que, para Ingold, representa a manifestação no interior da biologia do logocentrismo, na forma da suposição de que os fenômenos manifestos do mundo físico estão subscritos ao trabalho da razão), podese reconhecer que a cultura nele se imprime. Aí se coloca a problemática do embodiment ("encorporação"), que para Bateson (ao contrário, aqui, de Merleau-Ponty e de antropólogos por ele inspirados, como C sordas 1994) tem como suporte, não propriamente corpos, mas relações, padrões comunicativos. Mas ao mesmo tempo, mais radicalmente, pode-se dizer que em um plano fenomenológico, pré-objetivo, a cultura sequer existiria em si - e daí a centralidade da noção de skill —, o que, por sua vez, lembra a elaboração de Roy Wagner a respeito da (re)invenção da cultu- 
ra. Lembra também os signos não simbólicos de Peirce (o índice e o ícone), que antecipam um questionamento do postulado do arbitrário cultural.

Assim, não se trata mais uma vez de subordinar as ciências sociais às ciências da natureza, mas de realizar uma crítica da ciência ou pelo menos das imagens, poderosas, que se formam a seu respeito. Nisso, não se deve confundir inteiramente essas imagens com a prática científica como por vezes Ingold corre o risco de fazer - para não se incorrer numa espécie de "logocentrismo de segundo grau". Sair da defensiva. Etnografar, contextualizar, estabelecer as redes de comunicação do modo mais amplo possível são alguns dos procedimentos a serem estendidos ao terreno dos biólogos. As últimas e surpreendentes questões levantadas pelo desenvolvimento do Projeto G enoma parecem sugerir a sua pertinência. Sem que se subestime a nossa própria inconclusa tarefa de aprendizes na operacionalização de uma prática de pesquisa associada a essas idéias, podemos, sem dúvida, reconhecer estarmos diante de um campo de discussão estimulante e que, entre outras conseqüências, pode levar a antropologia a ocupar um lugar significativo nos debates científicos atuais.

Recebido em 13/7/01

Aprovado em 20/7/01

Otávio Velho é professor-titular do Programa de Pós-G raduação em Antropologia Social (PPGAS) do Museu Nacional/UFRJ. É autor de Besta-Fera: Recriação do Mundo (1995), entre outros, e ex-presidente da Associação Nacional de Pós-Graduação e Pesquisa em Ciências Sociais (ANPOCS).

\section{Nota}

* Agradeço a Amir G eiger, Hugo Lovisolo e Juarez Humberto Ferreira pelos generosos comentários. 


\section{Referências bibliográficas}

CSORDAS, Thomas J. (org.). 1994. Embodiment and Experience: The Existential Ground of Culture and Self. Cambridge: Cambridge University Press.

GIBSON, James. 1986 [1979]. The Ecological Approach to Visual Perception. London: Lawrence Erlbaum.

HARRIES-JONES, Peter. 1995. A Recursive Vision: Ecological Understanding and Gregory Bateson. Toronto: University of Toronto Press.

JONAS, Hans. 1996. Mortality and Morality: A Search for the Good after Auschwitz. Evanston: Northwestern University Press.

MATURANA, Humberto R. e VARELA, Francisco J. 1980. A utopoiesis and Cognition: The Realization of the Living. Dordrecht/Boston: D. Reidel. MERLEAU-PONTY, Maurice. 1971 [1945]. Fenomenologia da Percepção. Rio de Janeiro: Freitas Bastos. 1991 [1960]. "De Mauss a Claude Lévi-Strauss”. In: Signos. São Paulo: Martins Fontes. pp. 123-135.

REDDY, William M. 1997. “Against Constructionism: The Historical Ethnography of Emotions". Current Anthropology, 38(3):327-352.

REED, Edward S. 1988. "The Affordances of the Animate Environment: Social Science from the Ecological Point of View" . In: T. Ingold (org.), What Is an A nimal. London: Routledge. pp. 110-126.

SNOW, C. P. 1959. The Two Cultures and the Scientific Revolution. Cambridge: Cambridge University Press.

VELHO, Otávio. 1998. “Ensaio Herético sobre a Atualidade da G nose”. Horizontes Antropológicos, 4(8):34-52. 


\section{Resumo}

Em 2000 foi finalmente reeditado o mais importante livro de Gregory Bateson, Steps to an Ecology of Mind. Nesse mesmo ano, foi lançado o livro de Tim Ingold, The Perception of the Environment, que retoma muitas das preocupações de Bateson. Este ensaio considera que esses dois eventos marcam passos importantes na constituição de um "paradigma ecológico”, o qual vem responder a alguns dilemas que rondam a antropologia e abrir perspectivas para um diálogo interdisciplinar em novas bases. Palavras-chave Ecologia, Natureza, Cultura, Ciência, Meio Ambiente

\section{Abstract}

Gregory Bateson's most important book, Steps to an Ecology of M ind, was finally re-edited in 2000. In the same year, Tim Ingold's book, The Perception of the Environment, which takes up many of Bateson's preocupations, was released. This essay proposes that these two events represent important steps towards an "ecological paradigm", which attempts to answer some of anthropology's dilemas, and open up perspectives for interdisciplinary dialogue on new terms.

Key words Ecology, Nature, Culture, Science, Environment 